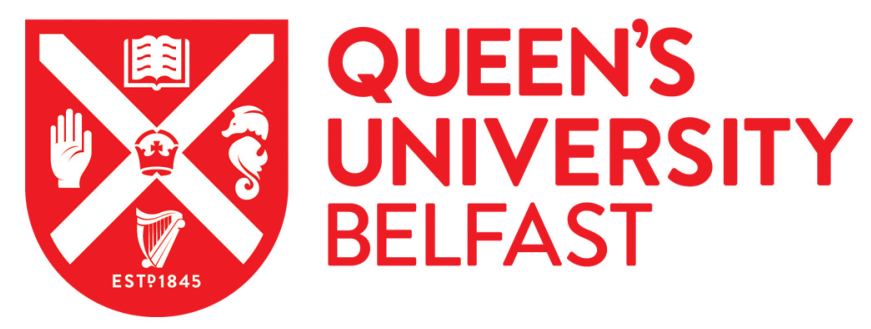

\title{
Informational needs of family caregivers of people with intellectual disability who require palliative care: a two-phase integrative review of the literature \\ McKibben, L., Brazil, K., Hudson, P., \& McLaughlin, D. (2019). Informational needs of family caregivers of people with intellectual disability who require palliative care: a two-phase integrative review of the literature. International Journal of Palliative Nursing, 25(1), 4-18. https://doi.org/10.12968/ijpn.2019.25.1.4
}

Published in:

International Journal of Palliative Nursing

Document Version:

Peer reviewed version

Queen's University Belfast - Research Portal:

Link to publication record in Queen's University Belfast Research Portal

Publisher rights

( $2019 \mathrm{MA}$ Healthcare Limited. This work is made available online in accordance with the publisher's policies. Please refer to any applicable terms of use of the publisher.

\section{General rights}

Copyright for the publications made accessible via the Queen's University Belfast Research Portal is retained by the author(s) and / or other copyright owners and it is a condition of accessing these publications that users recognise and abide by the legal requirements associated with these rights.

\section{Take down policy}

The Research Portal is Queen's institutional repository that provides access to Queen's research output. Every effort has been made to ensure that content in the Research Portal does not infringe any person's rights, or applicable UK laws. If you discover content in the

Research Portal that you believe breaches copyright or violates any law, please contact openaccess@qub.ac.uk. 


\section{International Journal of Palliative Nursing \\ Informational needs of family caregivers of people with intellectual disability who require palliative care: a two phase integrative review of the literature --Manuscript Draft--}

\begin{tabular}{|c|c|}
\hline Manuscript Number: & ijpn.2018.0067 \\
\hline Full Title: & $\begin{array}{l}\text { Informational needs of family caregivers of people with intellectual disability who } \\
\text { require palliative care: a two phase integrative review of the literature }\end{array}$ \\
\hline Short Title: & Information and palliative caregiving in intellectual disability \\
\hline Article Type: & Review \\
\hline Keywords: & Palliative care; intellectual disability; family caregiver, information needs, review \\
\hline Corresponding Author: & $\begin{array}{l}\text { Laurie McKibben, BSc, PhD } \\
\text { Queen's University Belfast } \\
\text { Belfast, UNITED KINGDOM }\end{array}$ \\
\hline \multicolumn{2}{|l|}{$\begin{array}{l}\text { Corresponding Author Secondary } \\
\text { Information: }\end{array}$} \\
\hline Corresponding Author's Institution: & Queen's University Belfast \\
\hline \multicolumn{2}{|l|}{$\begin{array}{l}\text { Corresponding Author's Secondary } \\
\text { Institution: }\end{array}$} \\
\hline First Author: & Laurie McKibben, BSc \\
\hline \multicolumn{2}{|l|}{ First Author Secondary Information: } \\
\hline \multirow[t]{4}{*}{ Order of Authors: } & Laurie McKibben, BSc \\
\hline & Kevin Brazil \\
\hline & Peter Hudson \\
\hline & Dorry McLaughlin \\
\hline \multicolumn{2}{|l|}{ Order of Authors Secondary Information: } \\
\hline Abstract: & $\begin{array}{l}\text { People with intellectual disabilities are living longer with increasingly complex needs, } \\
\text { their family caregivers may have a broad scope of unmet needs. This two phase } \\
\text { literature review utilised five electronic databases (CINAHL, PsycINFO, Medline, } \\
\text { Cochrane and Pubmed). Phase } 1 \text { involved a review of systematic reviews of the needs } \\
\text { of family caregivers across settings. Phase } 2 \text { explored the commonly reported } \\
\text { 'information needs' from phase } 1 \text {, in relation to family caregivers of people with } \\
\text { intellectual disability who require palliative care. There was no research explicit to the } \\
\text { information needs of these family caregivers. The review reveals potential information } \\
\text { needs which may exist, guided by the palliative caregiving literature; alluding to } \\
\text { information needs surrounding the disease, finances, and psychological or practical } \\
\text { support. It is surmised a greater scope of informational need exists for this population } \\
\text { and further research is of pertinence at international level. }\end{array}$ \\
\hline \multicolumn{2}{|l|}{ Suggested Reviewers: } \\
\hline \multicolumn{2}{|l|}{ Additional Information: } \\
\hline Question & Response \\
\hline $\begin{array}{l}\text { Please enter the word count of your } \\
\text { manuscript }\end{array}$ & 3889 \\
\hline
\end{tabular}




\title{
Informational needs of family caregivers of people with intellectual disability who require palliative care: a two phase integrative review of the literature
}

\section{Short title: Information and palliative caregiving in intellectual disability}

Laurie McKibben, PhD student ${ }^{1}$

Kevin Brazil, Professor ${ }^{1}$

Peter Hudson, Professor ${ }^{2}$

Dorry McLaughlin, Lecturer ${ }^{1}$

\author{
${ }^{1}$ School of Nursing and Midwifery, Queen's University Belfast, United Kingdom \\ ${ }^{2}$ Centre for Palliative Care, Centre for Palliative Care, St. Vincent's Hospital \& The University \\ of Melbourne, Fitzroy, Victoria, Australia
}

Corresponding author: Laurie McKibben, Iturner12@qub.ac.uk, 02890

\begin{abstract}
People with intellectual disabilities are living longer with increasingly complex needs, their family caregivers may have a broad scope of unmet needs. This two phase literature review utilised five electronic databases (CINAHL, PsycINFO, Medline, Cochrane and Pubmed). Phase 1 involved a review of systematic reviews of the needs of family caregivers across settings. Phase 2 explored the commonly reported 'information needs' from phase 1 , in relation to family caregivers of people with intellectual disability who require palliative care. There was no research explicit to the information needs of these family caregivers. The review reveals potential information needs which may exist, guided by the palliative caregiving literature; alluding to information needs surrounding the disease, finances, and psychological or practical support. It is surmised a greater scope of informational need exists for this population and further research is of pertinence at international level.
\end{abstract}




\section{Background}

Age UK (2017) assert that only one in seven people will be free from a long term condition by the time they reach their eighties. Consequently, the number of people providing unpaid care at home to a family member or friend is expeditiously increasing, with recent figures reporting an increase from $16.6 \%$ to $17.8 \%$ of the population between 2011 and 2015 (University of Essex 2015; Office for National Statistics (ONS) 2016).

Family caregivers are people who provide care for neighbours, relatives or friends who are dependent on them and who do not take payment for these services and they can also be known as informal carers (Thompson and Mathias 2008). These caregivers are now providing exceeding levels of care to people with increased complexity of needs (Age UK 2017).

As the population live longer they are also at increased risk of developing an advanced disease such as Cancer, Dementia, organ failure (including heart failure, end stage respiratory disease, liver failure or renal disease) or degenerative neurological disease, which requires palliative care (Radbruch and Payne 2009; WPCA and WHO 2014). Existing evidence emphasises the needs of family caregivers in palliative care, highlighting the impact of caregiving in relation to the physical, mental, social and financial burden, and the impact of this on their lives and society in general (Payne et al. 2010; Candy et al. 2011). 
Initial scoping searches of the literature revealed a paucity of evidence surrounding family caregivers of people with intellectual disabilities who require palliative care. A wider review of systematic reviews was first undertaken to identify all relevant literature in relation to family caregiver needs. Family caregivers of this population may have a broad scope of unmet needs, specifically information needs. A review with specific focus on the information needs of family caregivers of people with intellectual disabilities who require palliative care was then undertaken.

\section{Rationale for a two phase review}

Two phases were undertaken to cover the vast array of literature in relation to the needs of family caregivers in general, and to hone in on the specific information needs of family caregivers of people with intellectual disabilities in palliative care.

A review of systematic reviews of the needs of family caregivers was conducted for phase 1. Phase 2 further explored the commonly reported 'information needs' from the broader literature in phase 1, and applied this to family caregivers of people with intellectual disabilities who require palliative care.

\section{Overall Aims}

To identify the most common needs of family caregivers; to highlight gaps in the literature and distinguish the 'information needs' of family caregivers of people with intellectual disabilities who require palliative care. 
Phase 1 review of systematic reviews objectives were:

- To examine general 'needs' of family caregivers providing care to adults, from palliative care extending to those providing longer term care in chronic illness or intellectual disability.

- To reveal commonly cited needs.

- To identify under-researched subgroups of family caregivers.

Phase 2 literature review, adjunct to and informed by phase 1 in order to:

- Identify published research around the information needs of family caregivers of people with intellectual disabilities who require palliative care.

\section{Methods}

Phase 1 follows guidelines for systematic conduct and reporting, in line with Aveyard's (2014) systematic approach and PRISMA reporting (Moher et al. 2014).

\section{Search Strategy}

Both phases involved inspection of five electronic databases (CINAHL, PsycINFO, Medline, Cochrane and Pubmed). 


\section{Phase 1 Keywords:}

Family care ${ }^{*}$ to include carers and caregivers) OR Informal care* ( ${ }^{*}$ to include carers and caregivers) AND Needs AND Systematic Review.

Inclusion: Informal or family caregivers of adults over the age of 18 . Systematic Reviews or systematically conducted integrative reviews, as these are considered a subset of systematic reviews (Gunnarsson 2014). There were no restrictions applied on date or language.

Exclusion: Papers that did not meet the search criteria. Reviews that involved formal or paid caregivers, or caring for children rather than adults. Narrative and literature reviews.

There was a further hand search of pertinent journals and reference lists from seminal papers. Abstracts meeting initial criteria were screened and selected for full text retrieval based on relevance.

Selection and Quality Appraisal: Papers falling outside of the inclusion or exclusion criteria were rejected. Irrelevant or duplicate papers were also dismissed. Each review was critically appraised using the 10 question CASP (2018) systematic review checklist tool (www.casp-uk.net).

\section{Phase 1 Results}

Whilst there were many literature reviews and primary studies, a total of 16 systematic reviews were identified concerning the needs of family caregivers (figure 1). 


\section{Figure 1}

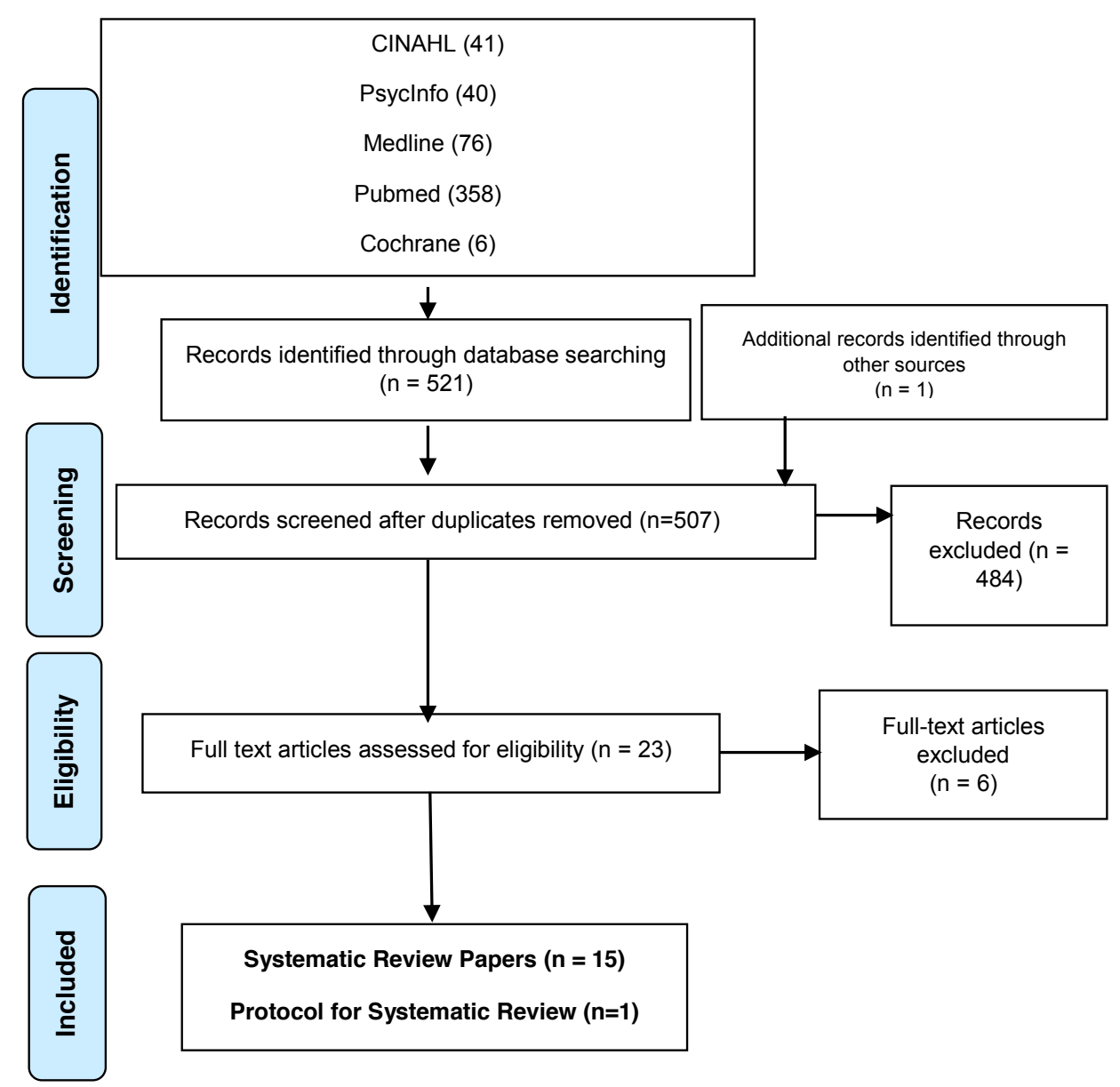




\section{Extraction of the data}

Systematic reviews revealed an international demographic spread:

$\mathrm{UK}=4$, Australia $=3$, Canada $=3$, United States $(U S)=2$, Spain $=1$, Portugal $=1$, France $=1$ and the Netherlands $=1$. Key characteristics of each review are presented in the data extraction table (Table 1).

\section{Results}

\section{Family caregiving populations across specialties}

Four systematic reviews (Innes et al. 2011; Afram et al. 2015; McCabe et al. 2016; Novais et al. 2017) and one protocol for systematic review (González-Fraile et al. 2015) were concerning family caregivers of people with Dementia. Three considered caregiving in palliative and end of life care (Docherty et al. 2008; Cagle et al. 2017; Rainsford et al. 2017).

Two reviews were specific to Cancer caregiving (Bee et al. 2009; Wheelright et al. 2015), and Lunsky et al. (2014) and Balogh et al. $(2008,2016)$ explored caregiving in intellectual disability. One review focused on post Stroke care (Forster et al. 2012), another, chronic health conditions (Washington et al. 2011), and a further review considered caring for elderly (Silva et al. 2013). 


\section{Commonly identified need for Information}

Analysis identified a running theme of information need/information provision for family caregivers. Information regarding available services, access to services and support, information on self-care, and information and signposting to psychosocial support were deemed important for family caregivers. Information was a common need and priority for family caregivers across caregiving populations. Moreover, a specific information need was surrounding the disease, its trajectory, and practical management.

Beaver and Witham (2007) suggest that the term 'information need' entails the recognition and assertion of poor provision or receipt of information. Sources agree that information has a recognised impact on how well a caregiver copes with the stress and burden associated with their role, including how information is delivered and by whom (Rose, 1999; Bee et al. 2009; Washington et al. 2011; Lunsky et al. 2014; Afram et al. 2015).

McCabe et al. (2016) concur with their predecessors Parker et al. (2007), Docherty et al. (2008) and Bee et al. (2009) and Afram et al. (2015) in recognising information as an important facilitator of services, support, and knowledge, to promote and enable caregiver competency. There is consensus that information is individualised depending on each family caregiver (Forster et al. 2012; Silva et al. 2013; Lunsky et al. 2014; Afram et al. 2015). 
Tailored information aids choice (Eysenbach 2000) and can facilitate holistic support inclusive of respite, education and training, financial assistance, and psychosocial support (DH 2008a; Philip et al. 2014). Across all settings information was seen as preparatory and a priority for health care providers.

Recommendations called for the provision of tailored information (Docherty et al. 2008; Washington et al. 2011, Lunksy et al. 2014; Afram et al. 2015). Balogh et al. (2008; 2016) also recommended specialised integrated support in the community to foster a more organised system of services and support provisions.

Findings across settings traverse due to some overlap of specialities and illnesses. Most reviews concerned Dementia/Alzheimer's (5) and palliative and end of life care, including end of life care in Cancer (4). Importantly, the WPCA and WHO (2014) categorise Dementia as a progressive disease, which may require palliative care in the advanced stages. Furthermore, Dementia is a co-morbid disease frequently associated with the ageing population of people with Down Syndrome (Towers and Glover 2015). Palliative care may also be prescribed for patients following acute stroke (Singh et al. 2017). 


\section{Discussion}

In seeking to scope the individualised needs of each population of caregivers including: those caring for people with dementia, cancer, intellectual disability, stroke, chronic health conditions, and for those who were elderly or required palliative care, there was moderate homogeneity of findings. 'Information needs' were most frequently reported. Furthermore, reviews reported other needs defined as psychological need, respite requirements, education on the illness, practical support, and financial assistance. All of which may be considered areas of information need. Some caregiving populations were under researched in relation to others, for example, the abundance of literature surrounding dementia, and palliative care, in comparison to intellectual disability or elderly stroke.

\section{Limitations}

Despite the breadth of insight and knowledge gained, limitations were identified through the CASP (2018) appraisal tool for systematic reviews. Structured quality assessment was not explicitly reported by Innes et al. (2011), Washington et al. (2011), Lunsky et al. (2014), Novais et al. (2017) and Cagle et al. (2017). Some reviews were limited by date (Innes et al. 2011; McCabe et al. 2016; Balogh et al. 2016; Rainsford et al. 2017), whilst others included published works only (Parker et al. 2007; Docherty et al. 2008; Innes et al. 2011; McCabe et al. 2016; Rainsford et al. 2017). 
A restriction on inclusion criteria may have excluded valuable evidence and limits generalisability of findings to similar populations. However, findings are valuable nonetheless due the systematic nature of the reviews

\section{Phase 1 Conclusion}

There were similarities in unmet needs identified, as well as corroborating evidence of the need for information. This phase also highlights family caregivers of people with intellectual disabilities as one of the comparatively under-researched groups. This is significant due to an increasing population of people with intellectual disabilities living into older age, with co-morbid conditions or advanced illnesses requiring palliative care. Crucially, the long term family caregivers of this population may be hidden to services, with their needs unknown (McLaughlin et al, 2014a; Tuffrey-Wijne et al. 2016).

The importance of identifying information needs of family caregivers of people with intellectual disabilities is strengthened by the recent population statistics. Figures suggest that long term family caregivers of people with intellectual disabilities may be faced with problems similar to caregiving in dementia, palliative care, Cancer, stroke or chronic illness, as the person they care for grows older (Kirkendall et al. 2012; Tuffrey-Wijne et al. 2016; Age UK 2017). 
Phase 1 demonstrates 'information needs' are common. Information is an important facilitator in supporting family caregivers. Applying this knowledge around information need to family caregivers of people with intellectual disabilities who require palliative care sheds light on which information needs may exist for these under researched family caregivers. Phase 2 seeks to examine the specific information needs of family caregivers of people with intellectual disabilities who require palliative care. 


\section{Phase 2 Background}

It is reported within the United Kingdom (UK) that Health and Social Care professionals have historically demonstrated insufficient knowledge, training or awareness of intellectual disability (Mencap 2007; Michael 2008; Heslop et al. 2013; Parliamentary and Health Service Ombudsman (PHSO) 2009, 2014). As a result, recommendations for 'reasonable adjustments' to care and support have been made in relation to the provision of meaningful care for people with intellectual disabilities and their caregivers, as vulnerable groups (PHSO 2009).

It is important to acknowledge that a late diagnosis for a palliative illness can occur in people with intellectual disability, due to lack of screening, or diagnostic overshadowing; the latter term is given where people may attribute symptoms or changes in behaviour to the intellectual disability, as opposed to an advanced co-morbid disease (Reiss et al. 1982; Heslop et al. 2013; Tuffrey-Wijne et al. 2016).

UK reports "Equal Lives" (DHSSPS 2005), "Healthcare for All" (Michael 2008), "Six Lives" (PHSO 2009), the "Confidential Inquiry into premature deaths of people with intellectual disabilities (CIPOLD)" (Heslop et al. 2013), "Dying without dignity" (PHSO 2014) and the more recent EAPC White Paper (Tuffrey-Wijne et al. 2016) have highlighted historical discrimination and access inequalities that have existed in the healthcare system for people with intellectual disabilities. 
Frequently cited issues around access to information and service provisions have a profound impact upon family caregivers. 'Living Matters, Dying Matters' (DHSSPS 2010) acknowledged the contribution of family caregivers in palliative care. It recognised the prevalence of chronic conditions, and the similar burden of symptoms to that of a malignant condition. Olson (2008) approached the importance of advance care planning and of family members as translators, who can interpret behaviours and language. Tuffrey-Wijne and Mclaughlin (2015) more recently provided consensus norms and standards for the provision of palliative care for people with intellectual disability, reflected in their EAPC White Paper (Tuffrey-Wijne et al. 2016).

European level policy and recommendations attempt to reduce pockets of marginalisation and assumptions, promoting the involvement and support of family caregivers in palliative care and intellectual disability (DH 2008a, 2008b; Radbruch and Payne 2010; Tuffrey-Wijne et al. 2016). However, services remain fragmented and difficult to access (McLaughlin et al. 2014b; Tuffrey-Wijne et al. 2016). This extends internationally (Kirkendall et al. 2012; Balogh et al. 2016). 
Phase 2 keywords:

Family care* OR Informal care*

AND

Intellectual disabilit* OR Learning Disabilit* OR Developmental disabilit $^{*}$

AND

OR Information OR Information needs

AND

\section{Palliative care OR End of life OR Hospice}

Inclusion: Published papers. Informal or family caregivers. Caregivers of adults over the age of 18 . No date restrictions.

Exclusion: Papers that did not meet the search criteria. Papers that involved formal caregivers, or caring for children.

Additional records identified were retrieved from hand searches of reference lists.

Selection and Quality Appraisal: Papers were assessed for quality and scored using the relevant CASP (2018) checklist (www.caspuk.net). Poor quality, irrelevant or duplicate papers were dismissed (figure 2). 


\section{Figure 2}

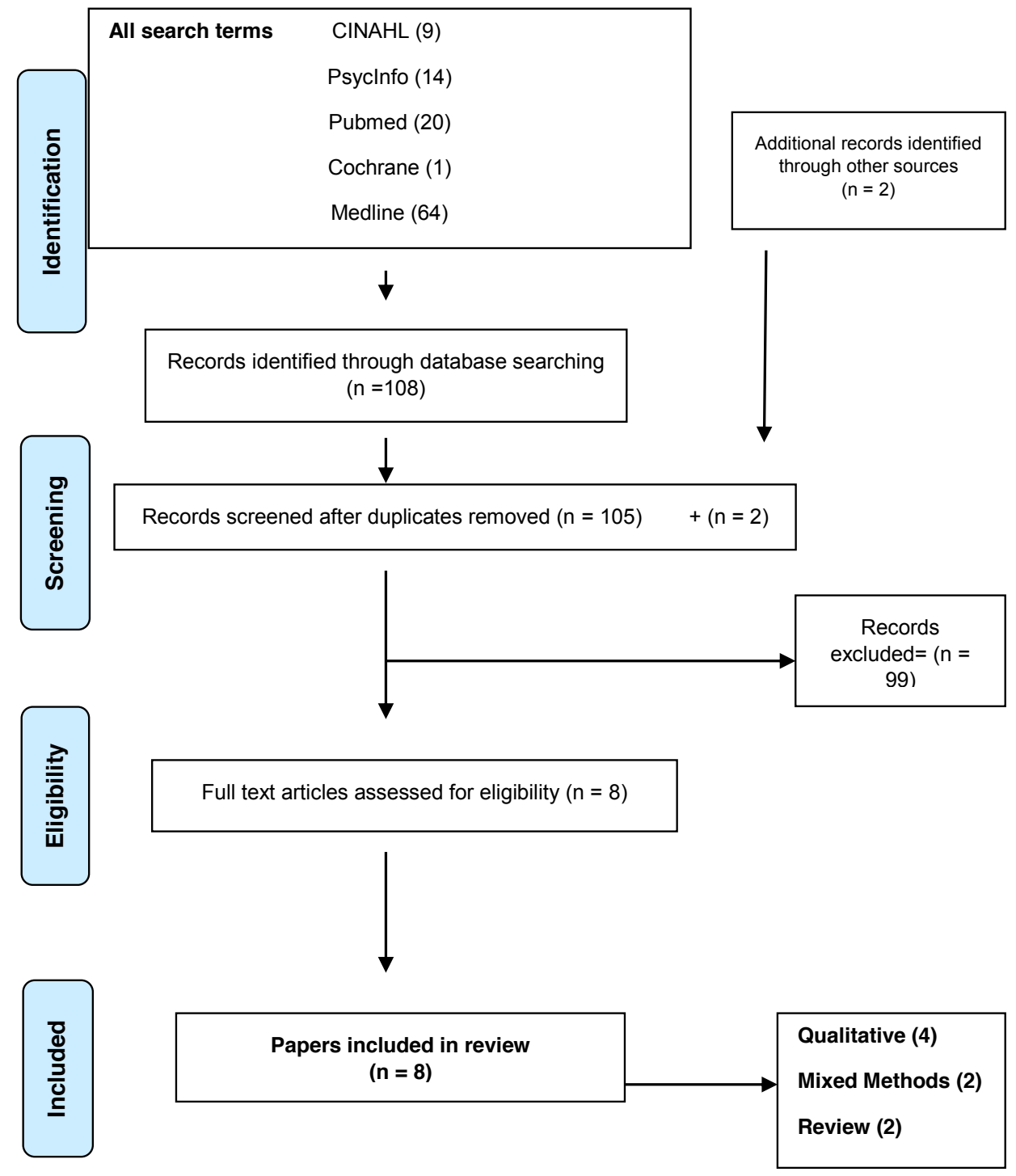




\section{Phase 2 Results}

8 published papers were identified for review. These papers are discussed alongside and in context to other relevant literature, government policies, and inquiry reports. Article demography revealed studies had taken place across a variety of countries, but were weighted within the UK: UK= 5, United States (US) $=1$, New Zealand $=1$ and the Netherlands $=1$. Details of the selected papers are provided in the data extraction table (Table 2).

\section{Connecting Services and Partnership Working}

Tuffrey-Wijne et al. (2007a) explored palliative care for people with intellectual disabilities and reported issues around diagnostic disclosures, presentation of symptoms, late diagnoses, poor communication, and ethical issues around decision making. Collaboration between intellectual disability and palliative care services and partnership work with family caregivers were highlighted. Training needs identified included carer information needs on the disease, and how to access palliative care services. Service planning, end of life decision making, and recognition of the psychosocial issues experienced by the person with intellectual disability and their family caregivers were also featured (Tuffrey-Wijne et al. 2007a). 
Similar issues surrounded the role of paid staff $(n=32)$ in the provision of palliative care for people with intellectual disabilities (Tuffrey-Wijne et al. 2007b). Study findings support other intellectual disability literature (Tuffrey-Wijne et al. 2007a; Lunsky et al. 2014; Balogh et al. 2016) in promoting identification of: family issues, assessment problems, emotional fears, and considering the effectiveness of good communication between staff, patient and carers. Tuffrey-Wijne et al. (2007b) recommended staff are trained in intellectual disability, and the expertise of the family caregivers recognised.

McLaughlin et al. (2014b) identified positive partnership working between intellectual disability and palliative care services, however, referrals to specialist palliative care were limited. The mixed methods study incorporated Health and Social Care professionals $(n=30)$ from both fields. Learning needs concurred with Tuffrey-Wijne et al. (2007a, 2007b) suggesting staff require better understanding of intellectual disability, supporting the carer, and coping with the aftermath of a diagnosis and/or death. A best practice model for partnership working was proposed, with development of improved training for professionals (McLaughlin et al. 2014b). 
Similarly concerning integration of services, Kirkendall et al. (2012) evaluated care for people with intellectual disability and life limiting illness, and recognised people with intellectual disabilities were living longer with little known about their end of life needs. In the United States, Kirkendall et al. (2012) acknowledged partnerships between intellectual disability services and palliative services were on the increase, yet the effectiveness of such was under researched. The authors argued that managing the care of someone with intellectual disability in the community employed divergent ideologies of care to palliative and end of life care services. Authors' further postulate that a disparity between fields and approaches creates issues for both disciplines and suggested partnership working and collaborative practice to promote information sharing and shared awareness.

In the Netherlands, Bekkema et al. (2015) also highlighted the importance of enhanced therapeutic relationships between the informal and paid carers. Study participants $(n=45)$ included family and Health and Social Care professionals who were involved with someone with intellectual disability at end of life. Important values identified were being responsive and reflective, and taking responsibility in cooperating in shared care. Family carers required support from professionals to make difficult decisions and teamwork was championed (Bekkema et al. 2015). 


\section{Accessibility and Equity of Information and Services}

McLaughlin et al. (2014b) attested to a gap in services and lack of accessibility for people with intellectual disability to quality end of life care. Recommendations were for services to be intertwined enabling access to the right services and information, for someone to die in their place of choice, and for continuity of care delivered by those familiar to them.

24 hour ongoing information and support for family caregivers of someone with intellectual disability who required end of life care was also valued and recommended in a small qualitative study $(n=5)$ conducted by Marlow and Martin (2008) in New Zealand. The study advocated sensitive communication between professionals and caregivers to facilitate this.

In relation to the education of professionals in palliative care and the support of people with intellectual disabilities, McLaughlin et al. (2014a) explored the perspectives of service users. Findings from focus groups ( $n=17)$ and semi structured interviews $(n=5)$ revealed key themes involving partnership, shared learning, support and empowerment, and issues and challenges at end of life. This study suggested early referrals to promote adequate information provision in a timely fashion, and the formation of trusting relationships. Late referrals remained an apparent barrier, however, to collaboration, information provision, and signposting to supportive interventions. 
More recently, Tuffrey-Wijne et al. (2016: 452-453) conducted a European Delphi study to assist drafting of norms for people with intellectual disabilities requiring palliative care. Norms included 'communication; equity of access; recognising the need for palliative care; assessment of total needs; end of life decision making, symptom management, involving those who matter; support for family and carers; collaboration; preparing for death; bereavement support; education and training, and developing and managing services.'

Tuffrey-Wijne et al. (2016) concluded a lack of data on people with intellectual disability who require palliative care. Recommendations included sharing of best practice, involvement of family caregivers, and modifications in policy in order for change. The recent White Paper (Tuffrey-Wijne and McLaughlin 2015, p54) suggests that palliative care services actively reach out to uncover this 'hidden' population in order to assess their needs, deliver support, and encourage carers' involvement as 'expert care partners.'

\section{Discussion}

Family caregiving research in the intellectual disability field is limited in comparison to palliative caregiving, and there were no studies identified specific to the information needs of family caregivers of people with intellectual disabilities who require palliative care. 
Tuffrey-Wijne et al. (2007a) focused on the person with a disability as opposed to the family caregiver and Tuffrey-Wijne et al.'s (2007b) primary study explored only the role of paid staff, as did the Bekkema et al. (2015) study. However, both papers provide insight and knowledge into the role of family caregivers and importance of paid staff supporting family caregivers in meeting potential information and support needs.

Some research concerned small numbers of participants (Marlow and Martin 2012; McLaughlin et al. 2014a), however due to the exploratory qualitative designs, findings provided rich information also important to understanding the potential information needs of family caregivers of people with intellectual disabilities who require palliative care. In particular, Marlow and Martin (2008) offer a window into the world of a family caregiver of someone with intellectual disability who is dying; however, further exploratory work with a larger sample is warranted.

Tuffrey-Wijne et al. (2016) support Kirkendall et al.'s (2012) assertion that if each field identifies the other's similar philosophy of care then there will be intermutual harmony, which will benefit family caregivers in addressing their needs. Within the UK, the philosophy of a 'good death' (DH 2010b) in palliative care is similar to the philosophy of living a 'good life' within the intellectual disability field (BILD 2015). These congruent philosophies promote the benefits of joint working for people with intellectual disabilities who require palliative care, and their family caregivers (Kirkendall et al. 2012; McLaughlin et al. 2014a). 
Kirkendall et al. (2012) and McLaughlin et al. (2014a) both promote adequate information provision through good communication and partnership working across fields.

\section{Limitations}

The majority of literature was UK based which may not be a reflection of the status of the needs of family caregivers in other countries, due to the nature of how government systems and health care services are organised elsewhere. There was no reporting of quality of material reviewed in the Tuffrey-Wijne et al. (2007a) paper, dates were also limited from 1995-2005 meaning useful material may have been overlooked. However, as there was such little research at the interface of intellectual disability and palliative care services at that time, the evidence remains advantageous.

\section{Phase 2 Conclusion}

This review highlights the gap in the research in relation to the specific informational needs of family caregivers of people with intellectual disabilities who require palliative care. It sheds light however on what informational needs may exist based on the evidence retrieved. The scope of information required may be extensive and dependent on the individual caregiver at the interface of intellectual disability and palliative care services, taking into account the existing and lengthy care trajectory associated with caring for someone with intellectual disability, prior to a palliative diagnosis. 


\section{Implications for Practice and Future Research}

A palliative diagnosis may compound any existing carer burden associated with the complex care of someone with an intellectual disability (Kirkendall et al. 2012). Supporting populations of family caregivers, such as those providing care to people with intellectual disabilities who require palliative care, by identifying and addressing their informational needs, fosters improved quality of life and meaningful fiscal and societal contribution.

\section{Overall conclusions}

There is a wide body of international literature concerning palliative caregiving in comparison to family caregivers of people with intellectual disabilities, in general. 'Information needs' were most commonly identified with other caregiving populations across specialities, including disease specific information, practical information and financial information.

We also know that access to information and equity of available services remain barriers to meeting the information needs of family caregivers comprehensively, across settings in various countries. We do not however know the specific information needs of family caregivers of people with intellectual disabilities who require palliative care, highlighted by the gap in the literature in phase 2 . 
Crucially, the needs of people with intellectual disabilities who require palliative care, and their family caregivers, are of importance at European level and a policy direction priority (Tuffrey-Wijne et al. 2016). Internationally, this cohort of family caregivers may be hidden to services; it is therefore important that further research is conducted to ascertain if similar information needs exist, and how they can be addressed.

\section{References}


Age UK (2017) Briefing: Health and Care of Older People in England 2017. https://www.ageuk.org.uk/documents/EN-GB/Forprofessionals/Research/The Health and Care of Older People in England 2016.pdf?dtrk=true (accessed 10 July 2018)

Afram B, Verbeek H, Bleijlevens MHC, Hamers JPH (2015) Needs of informal caregivers during transition from home towards institutional care in dementia: a systematic review of qualitative studies. Int Psychogeriatr 27(6): 891-902

Aveyard H (2014) Doing a Literature Review in Health and Social Care: a practical guide. 3rd ed. Maidenhead (UK): Open University Press

Balogh R. Ouellette-Kuntz H, Bourne L, Lunsky Y, Colantonio A (2008) Organising health care services for persons with an intellectual disability. Cochrane Database Syst Rev 4. Art. No.: CD007492

Balogh R, McMorris CA, Lunsky Y, Oullette-Kuntz H, Bourne L, Colantonio A, Gonçalves-Bradley DC (2016) Organising healthcare services for persons with an intellectual disability. Cochrane Database Syst Rev 4. Art.No.:CD007492.

Beaver K, Witham G (2007) Information needs of the informal carers of women treated for breast cancer. Eur J Oncol Nurs 11: 16-25. Doi: 10.1016/j.ejon.2006.01.006

Bee PE, Barnes P, Luker KA (2009) A systematic review of informal caregivers' needs in providing home-based end-of-life care to people 
with cancer. J Clin Nurs 18(10): 1379-1393. Doi: 10.1111/j.13652702.2008.02405.x

Bekkema N, de Veer AJE, Hertogh CMPM, Francke AL (2015) From activating towards caring: shifts in care approaches at the end of life of people with intellectual disabilities; a qualitative study of the perspectives of relatives, care-staff and physicians. BMC Palliat Care 14(1): 1-10. Doi: 10.1186/s12904-015-0030-2

Belfast Health and Social Care Trust (2017) "Caring together in Belfast" - A plan for supporting carers in Belfast 2017-2020. http://www.belfasttrust.hscni.net/pdf/1414 Carers Plan 2016 ONLINE version.pdf (accessed 19 July 2018) [BILD] British Institute of Learning Disabilities (2015) Living a Good Life. http://www.bild.org.uk/news-and-whats-on/national-ld-show-andawards/living-a-good-life/ (accessed 20 July 2018)

Cagle JG, Bunting M, Kelemen A, Lee J, Terry D, Harris R (2017) Psychosocial needs and interventions for heart failure patients. Heart Fail Rev 22: 565-580. Doi: 10.1007/s10741-017-9596-5

Candy B, Jones L, Drake R, Leurent B, King M (2011) Interventions for supporting informal caregivers of patients in the terminal phase of a disease (Review). Cochrane Database of Syst Rev 15(6): 1-63. Doi: 10.1002/14651858.CD007617.pub2 (CASP) Critical Appraisal Skills Programme (2017) CASP Checklists. http://www.casp-uk.net/casp-tools-checklists (accessed 23 June 2018) 
(DH) Department of Health (2008a) Carers at the heart of 21stcentury families and communities: "A caring system on your side. A life of your own."

https://www.gov.uk/government/uploads/system/uploads/attachment data/file/136492/carers at the heart of 21 century families.pdf (accessed 10 July 2018)

(DH) Department of Health (2008b) End of Life Care Strategy: Promoting high quality care for all adults at the end of life. https://www.gov.uk/government/uploads/system/uploads/attachment data/file/136431/End of life strategy.pdf (accessed 15 July 2018) (DHSSPS) Department of Health, Social Services and Public Safety (2005) Equal Lives : Review of Policy and Services For People with a Learning Disability in Northern Ireland.

http://www.dhsspsni.gov.uk/equallivesreport.pdf (accessed 15 July 2018)

(DHSSPS) Department of Health, Social Services and Public Safety (2010) "Living Matters: Dying Matters." A Palliative and End of Life Care Strategy for Adults in Northern Ireland | Northern Ireland Supportive \& Palliative Care Network. https://www.healthni.gov.uk/sites/default/files/publications/dhssps/living-matters-dyingmatters-strategy-2010.pdf (accessed 15 July 2018) Docherty A, Owens A, Asadi-Lari M, Petchey R, Williams J, Carter YH (2008) Knowledge and information needs of informal caregivers 
in palliative care: a qualitative systematic review. Palliat Med 22(2):153-171. Doi: 10.1177/0269216307085343

Eysenbach G (2000) Consumer health informatics. Br Med J 320:

1713-1716. Doi: 10.1136/bmj.320.7251.1713

Forster A, Brown L, Smith J, House A, Knapp P, Wright JJ, Young J (2012) Information provision for stroke patients and their caregivers. Cochrane Database Syst Rev 11. Art. No.: CD001919. Doi: 10.1002/14651858.CD001919.pub3

González-Fraile E, Solà I, Ballesteros J, Rueda JR, Martinez G, Santos B (2015) Information, support and training for informal caregivers of people with dementia (Protocol)' Cochrane Databas Syst Rev 10. Art. No.: CD006440. Doi:

10.1002/14651858.CD006440.pub2

Gunnarsson R (2014) Writing a systematic review. http://sciencenetwork.tv/writing-a-systematic-review/ (accessed 7 June 2018)

Harrop E, Byrne A, Nelson A (2014) It's alright to ask for help: findings from a qualitative study exploring the information and support needs of family carers at the end of life. BMC Palliat Care 13(1): 1-22. Doi.org/10.1186/1472-684X-13-22

Heslop P, Blair P, Fleming, P, Hoghton M, Marriott A, Russ L (2013) Confidential Inquiry into premature deaths of people with learning 
disabilities (CIPOLD). https://rcpsych.ac.uk/pdf/Confidential Inquiry into premature deaths full report.pdf (accessed 27 June 2018)

Hudson P, Aranda S (2013) The Melbourne Family Support Program: evidence-based strategies that prepare family caregivers for supporting palliative care patients. BMJ Support Palliat Care 0: 1-7. Doi: 10.1136/bmjspcare-2013-000500

Innes A, Morgan D, Kostineuk J (2011) Dementia care in rural and remote settings: A systematic review of informal/family caregiving. Maturitas 68(1): 34-46. Doi: 10.1016/j.maturitas.2010.10.002

Kirkendall AM, Waldrop D, Moone R (2012) Caring for People With Intellectual Disabilities and Life-Limiting IIIness: Merging PersonCentered Planning and Patient-Centered, Family-Focused Care. J Soc Work End Life Palliat Care 8(2): 135-150. Doi:

$10.1080 / 15524256.2012 .685440$

Lunsky Y, Tint A, Robinson S, Gordeyko M, Ouellette-Kuntz H (2014) System-Wide Information About Family Carers of Adults with Intellectual/Development Disabilities-A Scoping Review of the Literature. J Policy Pract Intellect Disabil 11(1) 8-18.

Marlow S, Martin M (2008) A voyage of grief and beauty: supporting a dying family member with an intellectual disability. Int J Palliat Nurs 14(7): 342-349. Doi: $10.12968 /$ ijpn.2008.14.7.30620

McCabe M, You E, Tatangelo G (2016) Hearing Their Voice: A Systematic Review of Dementia Family Caregivers' Needs. Gerontologist 56(5): e70-e88. Doi: 10.1093/geront/gnw078 
McLaughlin D, Barr O, Mcllfatrick S, McConkey R (2014a) Service user perspectives on palliative care education for health and social care professionals supporting people with learning disabilities. BMJ Support Palliat Care 0: 1-7. Doi: 10.1136/bmjspcare-2013-000615

McLaughlin D, Barr O, Mcllfatrick S, McConkey R (2014b) Developing a best practice model for partnership practice between specialist palliative care and intellectual disability services: A mixed methods study. Palliat Med 28:1213-1221. Doi:

$\underline{10.1177 / 0269216314550373}$

Mencap (2007) Death by indifference.

https://www.mencap.org.uk/death-by-indifference (accessed 15 July 2018)

Mencap (2012) Death by indifference: 74 deaths and counting: A progress report 5 years on.

https://www.mencap.org.uk/sites/default/files/2016-

08/Death $\% 20$ by $\% 20$ Indifference $\% 20$ -

\%2074\%20deaths\%20and\%20counting.pdf (accessed 18 July 2018)

Michael J (2008) Healthcare for All: Report of the independent inquiry into access to healthcare for people with learning disabilities. http://webarchive.nationalarchives.gov.uk/20130107105354/http:/ww w.dh.gov.uk/prod consum dh/groups/dh digitalassets/@dh/@en/do cuments/digitalasset/dh 106126.pdf (accessed 15 July 2018) 
Moher D, Liberati A, Tetzlaff J, Altman DG (2014) Preferred

Reporting Items for Systematic Reviews and Meta-Analyses. Ann

Intern Med 151: 264-269. Doi: 10.1371/journal.pmed1000097

Novais T, Dauphinot V, Krolak-Salmon P, Mouchoux C (2017) How

to explore the needs of informal caregivers of individuals with

cognitive impairment in Alzheimer's disease or related diseases? A

systematic review of quantitative and qualitative studies. BMC Geriatr

17(860: 1-18. Doi: 10.1186/s12877-017-0481-9

(ONS) Office for National Statistics (2016) Population estimates for

UK, England and Wales, Scotland and Northern Ireland

https://www.ons.gov.uk/peoplepopulationandcommunity/populationan

dmigration/populationestimates/bulletins/annualmidyearpopulationest

imates/mid2015 (accessed 10 June 18)

Olson S (2008) Caring at the end of life. Exceptional Parent 38(11):

44-46.

http://search.ebscohost.com/login.aspx?direct=true\&db=jlh\&AN=201

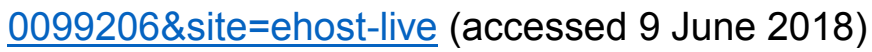

(PHSO) Parliamentary and Health Service Ombudsman (2009) Six

lives : the provision of public services to people with learning

disabilities Part one : overview and summary investigation reports

https://www.gov.uk/government/uploads/system/uploads/attachment

data/file/250750/0203.pdf (accessed 26 June 2018) 
(PHSO) Parliamentary and Health Service Ombudsman (2014) Dying without dignity: Investigations by the Parliamentary and Health Service Ombudsman into complaints about end of life care. https://www.ombudsman.org.uk/sites/default/files/Dying without dign ity.pdf (accessed 26 June 2018)

Payne S, Hudson P, Grande G, Oliviere D, Tishelman C, Pleschberger C, Firth P, Ewing G, Hawker S, Kerr C (2010) EAPC Family Carers in Palliative Care White Paper: Part 1. Eur J Palliat Care 17(5): 238-245.

Payne S, Hudson P, Grande G, Oliviere D, Tishelman C, Pleschberger C, Firth P, Ewing G, Hawker S, Kerr C (2010) EAPC Family Carers in Palliative Care White Paper: Part 2. Eur J Palliat Care 17(5): 286-290.

Philip J, Gold M, Brand C, Miller B, Douglass J, Sundararajan V (2014) Facilitating Change and Adaption: The Experiences of Current and Bereaved Carers of Patients with Severe Chronic Obstructive Pulmonary Disease. J Palliat Med 17(4): 421-427. Doi:

10.1089/jpm.2013.0339

Radbruch L, Payne S (2009) EAPC White Paper on standards and norms for hospice and palliative care in Europe: Part 1. Eur J Palliat Care 16(6): 278-289.

http://www.eapcnet.eu/Themes/Organisation/EAPCStandardsNorms. aspx (accessed 12 July 2018) 
Radbruch L, Payne S (2010) EAPC White Paper on standards and norms for hospice and palliative care in Europe: Part 2.' Eur J Palliat Care 17(1): 22-32.

http://www.eapcnet.eu/Themes/Organisation/EAPCStandardsNorms. aspx (accessed 12 July 2018)

Rainsford S, MacLeod RD, Glasgow NJ, Phillips CB, Wiles RB, Wilson D (2017) Rural end-of-life care from the experiences and perspectives of patients and family caregivers: A systematic literature review. Palliat Med 31(10): 895-912. Doi:

$10.1177 / 0269216316685234$

Reiss S, Levitan GW, Szyszko J (1982) Emotional disturbance and mental retardation: diagnostic overshadowing. Am J of Ment Defic 87(4): 369-402.

Rose KE (1999) A qualitative analysis of the information needs of informal carers of terminally ill cancer patients. J Clin Nurs 8: 81-88. Doi: 10.1046/j.1365-2702.1999.00214.x

Sherman DW, McGuire DB, Free D, Cheon JY (2014) A pilot study of the experience of family caregivers of patients with advanced pancreatic cancer using a mixed methods approach. J Pain Symptom Manage 48(3): 385-399. Doi:

10.1016/j.jpainsymman.2013.09.006 
Silva AL, Teixeira HJ, Teixeira MJC, Freitas S (2013) The needs of informal caregivers of elderly people living at home: an integrative review. Scand J Caring Sci 27: 792-803. Doi: 10.1111/scs.12019

Singh T, Peters SR, Tirschwell DL, Creutzfeldt CJ (2017) Palliative Care for Hospitalized Patients With Stroke: Results From the 2010 to 2012 National Inpatient Sample. Stroke 48(9): 2534-2540. Doi:

\subsection{1/STROKEAHA.117.016893}

Thompson T, Mathias P(1998) Standards and Learning Disability (2nd ed). London: Balliere Tindall.

Towers C, Glover C (2015) Talking Together: Facilitating peer support activities to help people with learning disabilities understand about growing older and living with dementia.

http://www.learningdisabilities.org.uk/publications/talking-together/ (accessed 23 June 2018)

Tuffrey-Wijne I, Hogg J, Curfs, I (2007a) End-of-Life and Palliative Care for People with Intellectual Disabilities Who have Cancer or Other Life-Limiting IIIness: A Review of the Literature and Available Resources. J Appl Res Intellect Disabil 20(4): 331-344. Doi:

10.1111/j.1468-3148.2006.00350.x

Tuffrey-Wijne I, McEnhill L, Curfs L, Hollins S (2007b) Palliative care provision for people with intellectual disabilities: interviews with specialist palliative care professionals in London. Palliat Med 21(6): 493-499. Doi: $10.1177 / 0269216307082019$ 
Tuffrey-Wijne, I, McLaughlin D (2015) Consensus Norms for

Palliative Care of People with Intellectual Disabilities in Europe EAPC White Paper Taskforce on People with Intellectual Disabilities.

London: EAPC.

Tuffrey-Wijne I, McLaughlin D, Curfs L, Dusart A, Hoenger C,

McEnhill L, Read S, Ryan K, Satgé D, Straßer B et al (2016) Defining consensus norms for palliative care of people with intellectual disabilities in Europe, using Delphi methods: A White Paper from the European Association of Palliative Care. Palliat Med 30(5): 446-455. Doi: $10.1177 / 0269216315600993$

University of Essex. Institute for Social and Economic Research and NatCen Social Research (2015) Understanding Society: Waves 1-5, 2009-2014 (7th ed). Essex: UK Data Archive. Doi: 10.5255/UKDASN-6614-7

Washington KT, Meadows SE, Elliott SG, Koopman RG (2011) Information needs of informal caregivers of older adults with chronic health conditions. Patient Educ Couns 83: 37-44. Doi:

10.1016/j.pec.2010.04.017

Wheelwright S, Darlington A, Hopkinson JB, Fitzsimmons D, Johnson C (2016) A systematic review and thematic synthesis of quality of life in the informal carers of cancer patients with cachexia. Palliat Med 30(2): 149-160. Doi: 10.1177/0269216315588743 
(WPCA and WHO) Worldwide Palliative Care Alliance and World Health Organisation (2014) Global Atlas of Palliative Care at the End of Life. (Connor, S.R. and Sepulveda Bermedo, M.C. Ed) http://www.who.int/nmh/Global Atlas of Palliative Care.pdf (accessed 18 June 2018) 
Figure 1

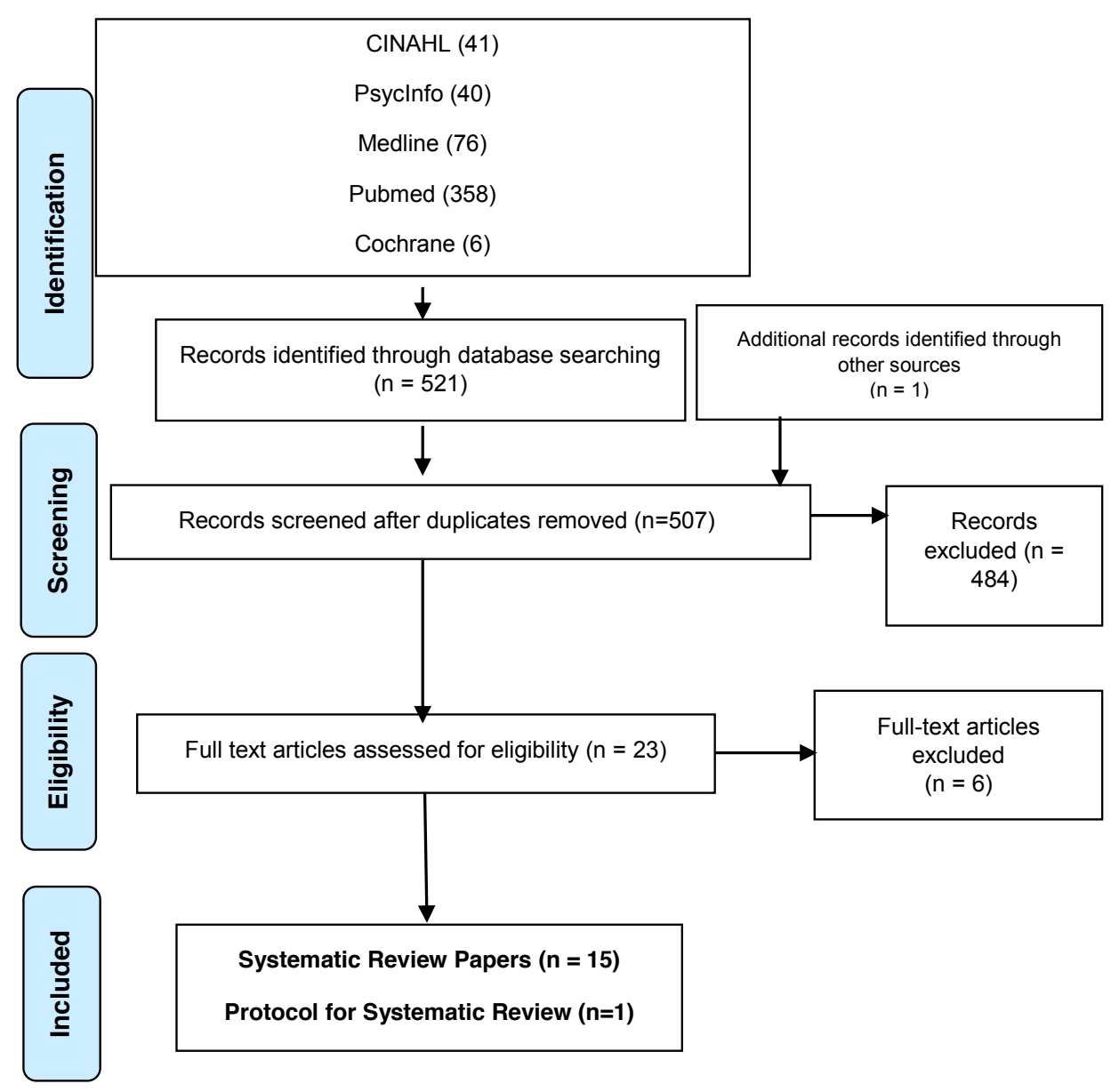




\section{Figure 2}

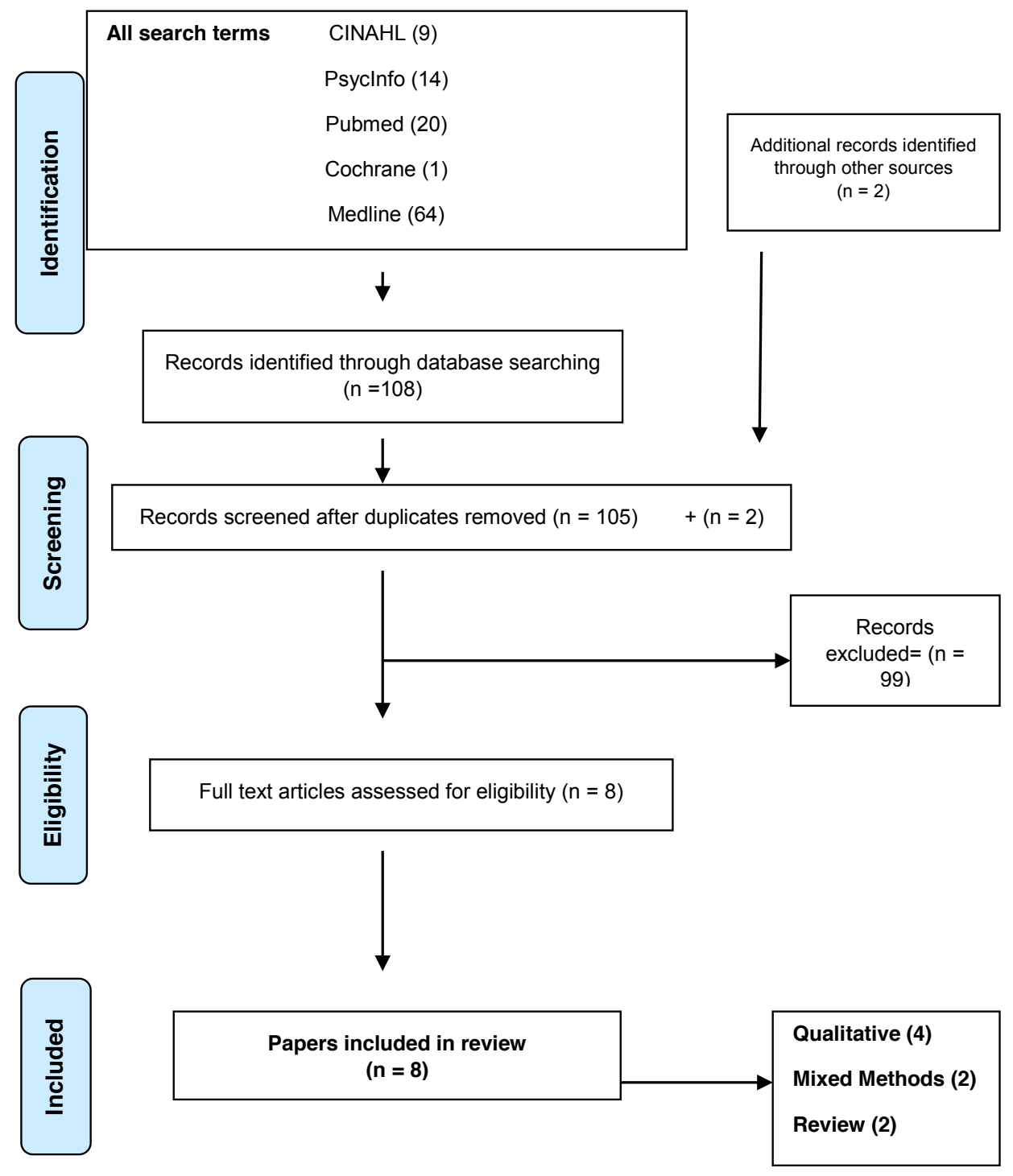




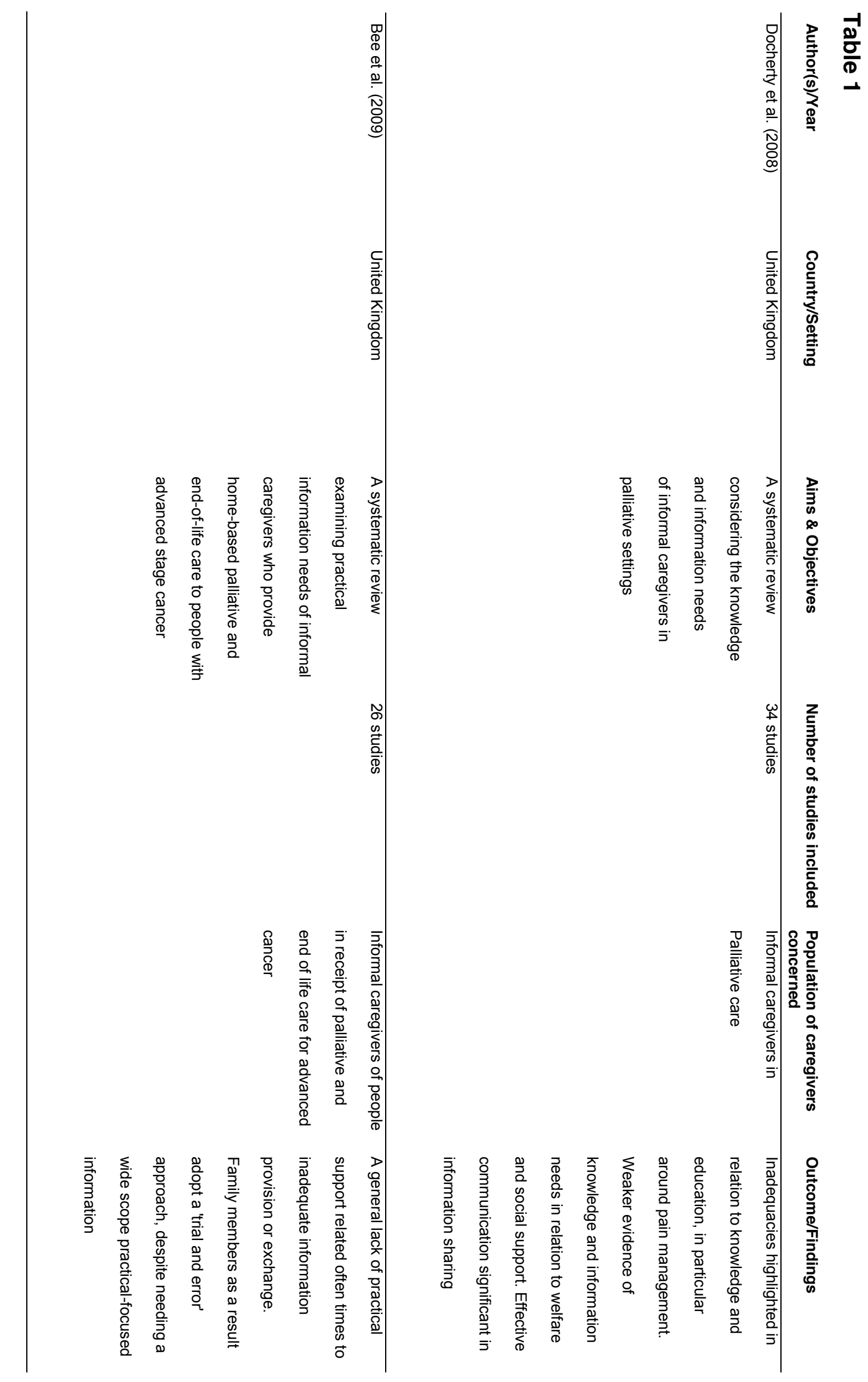




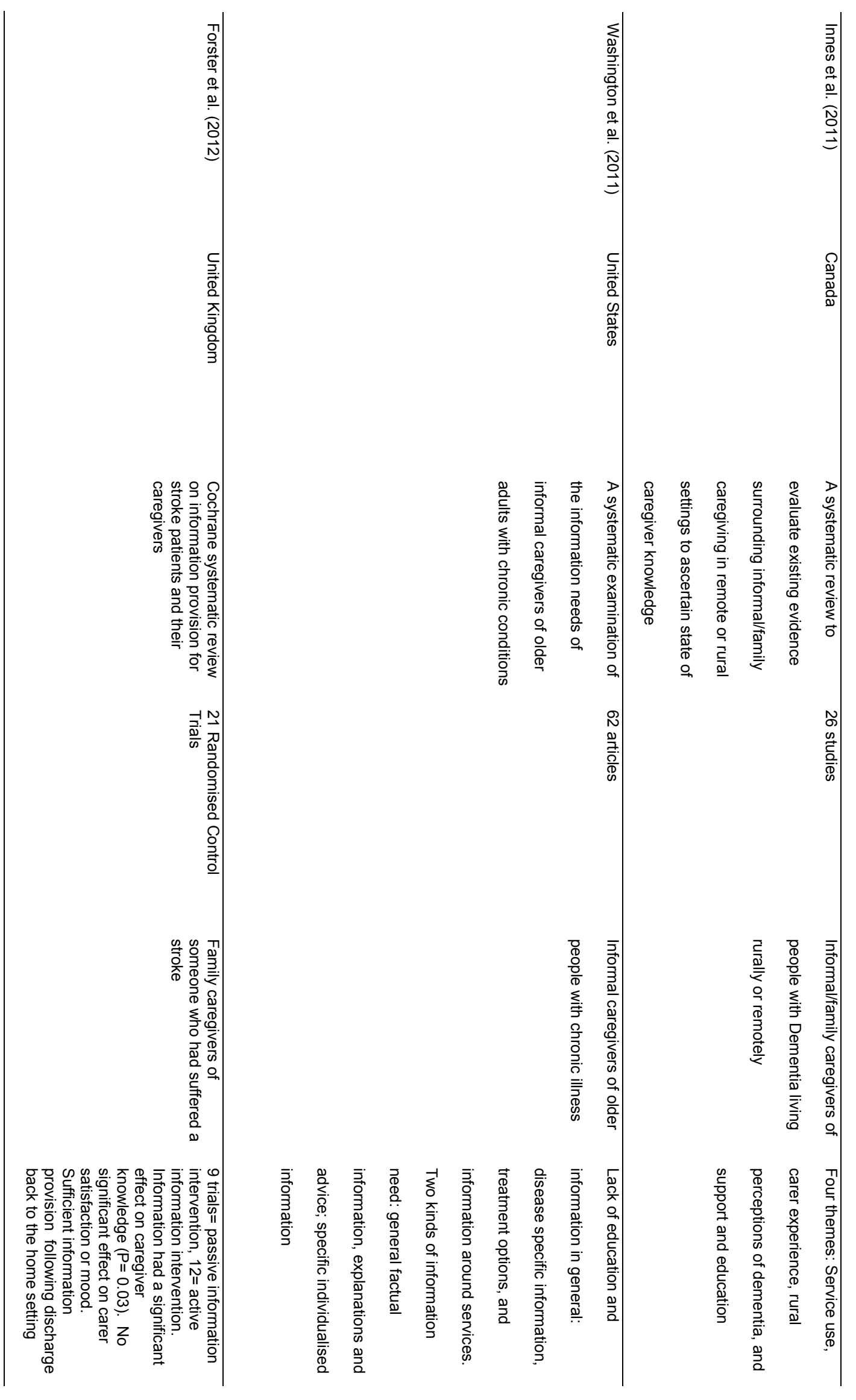




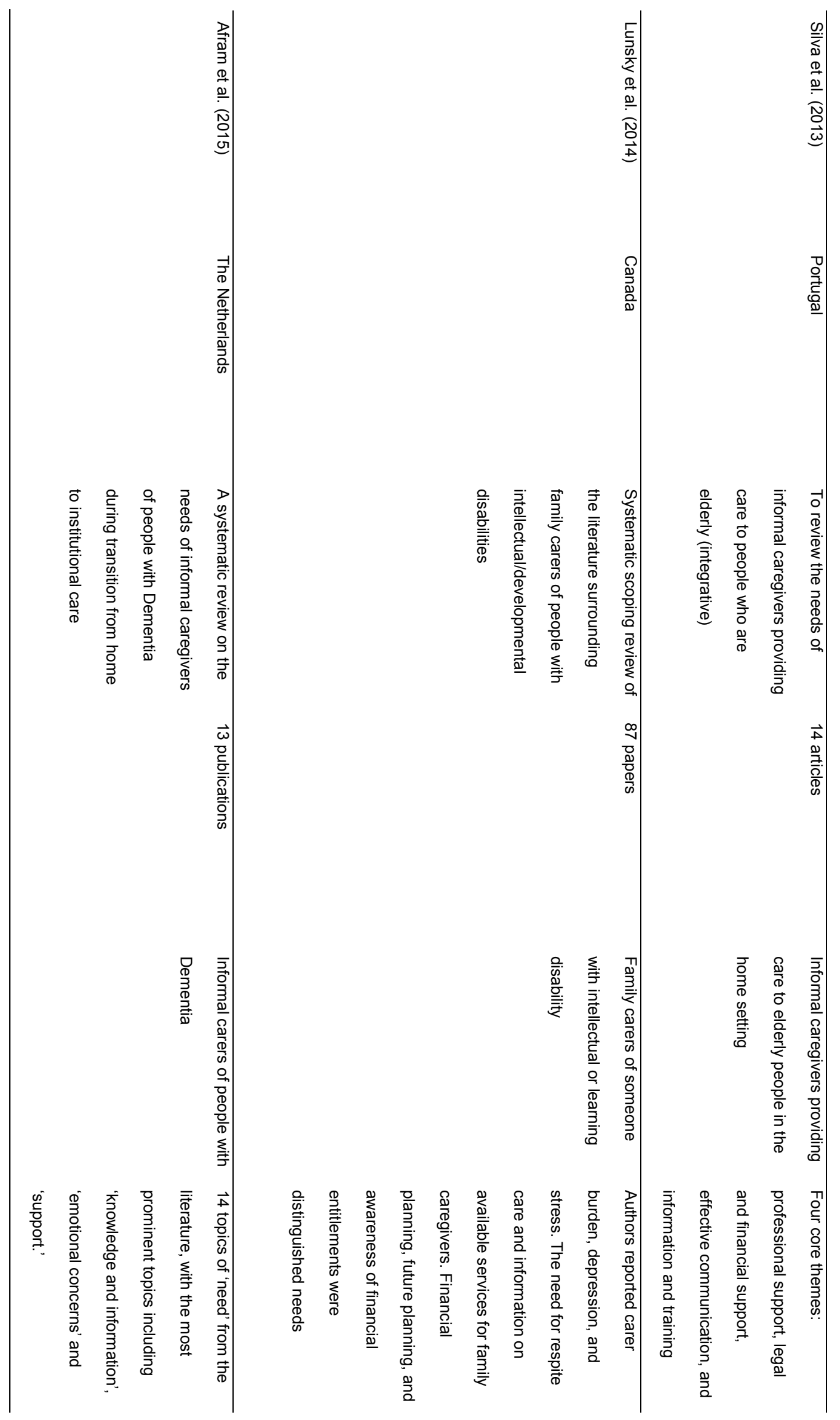




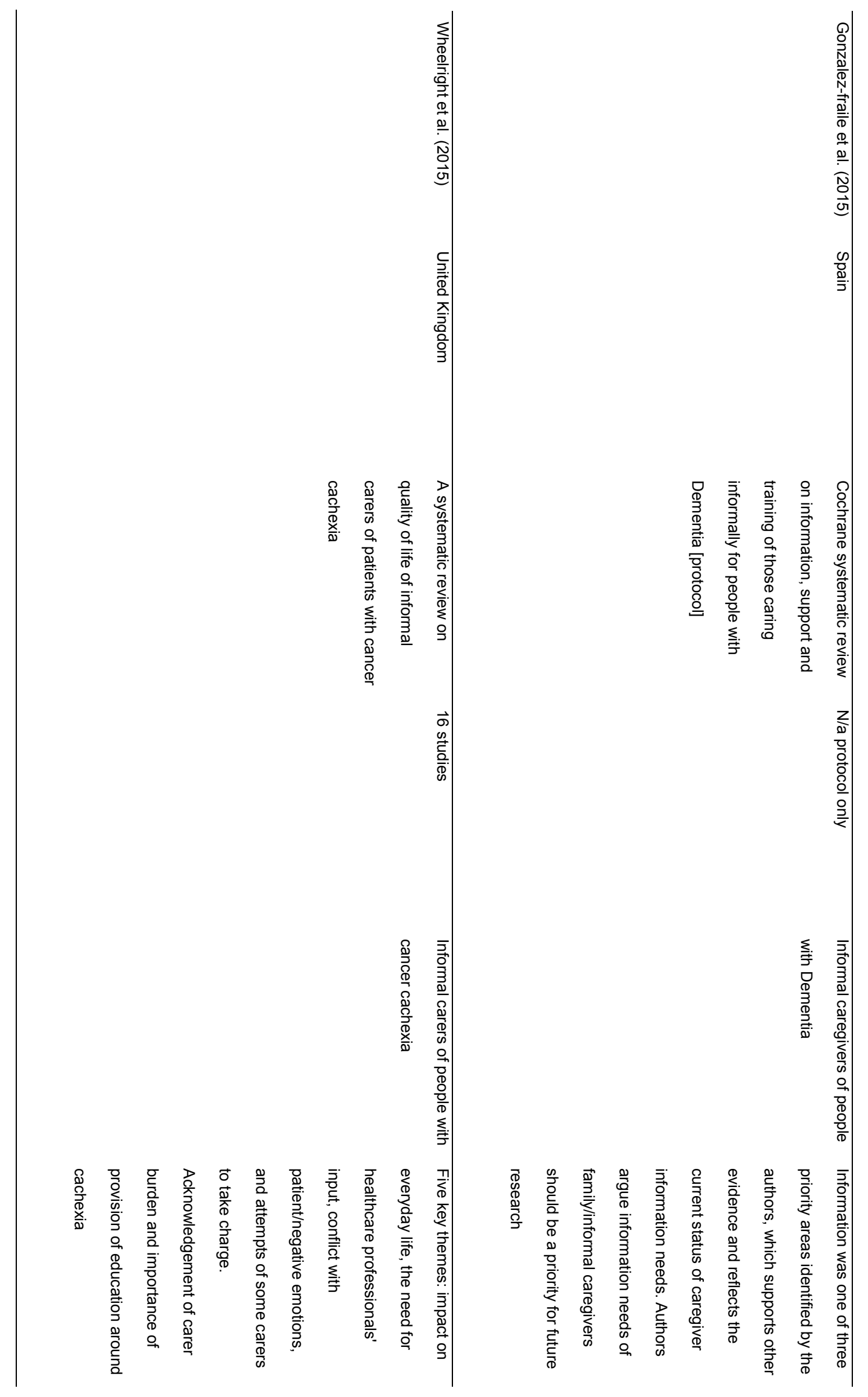




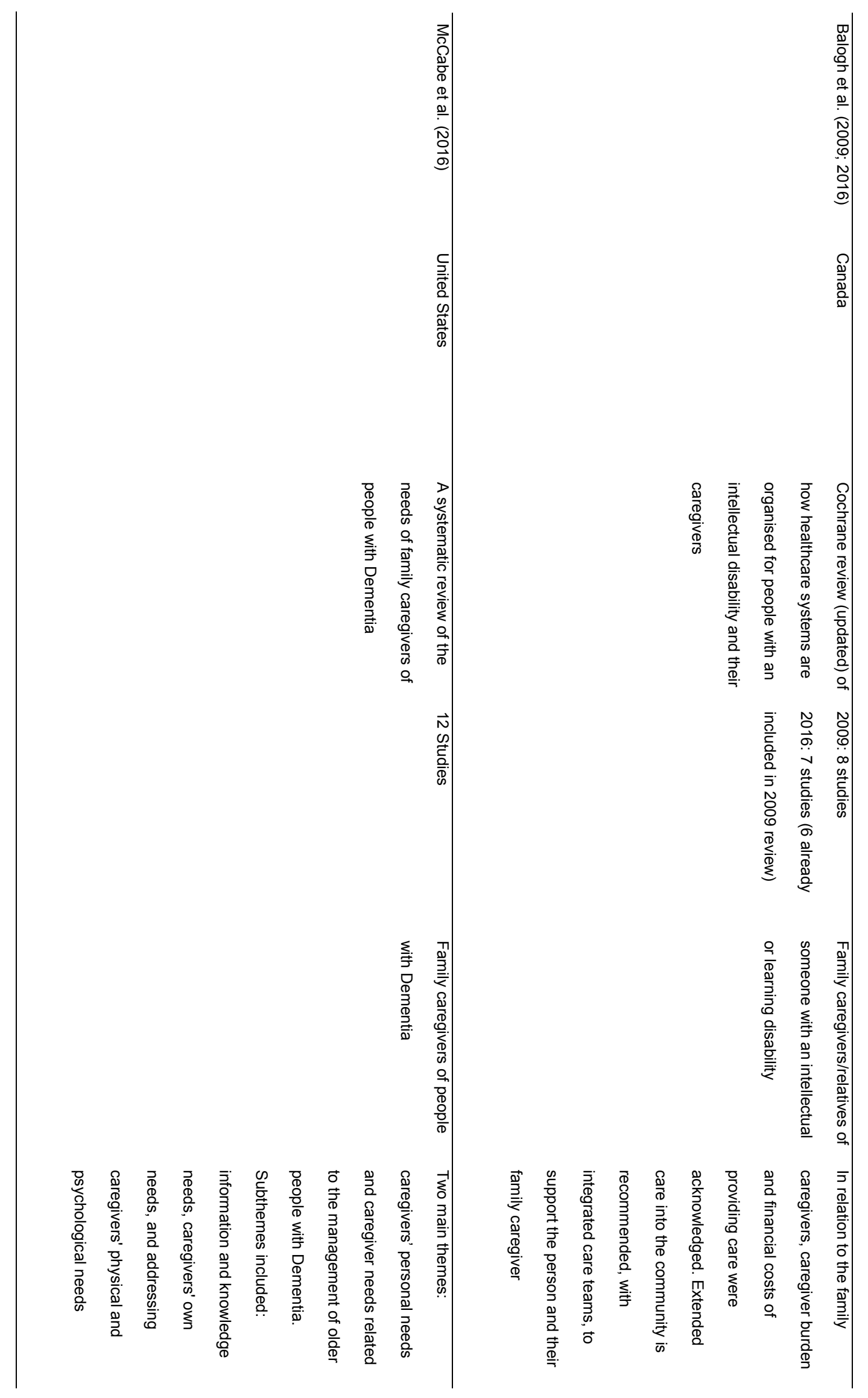




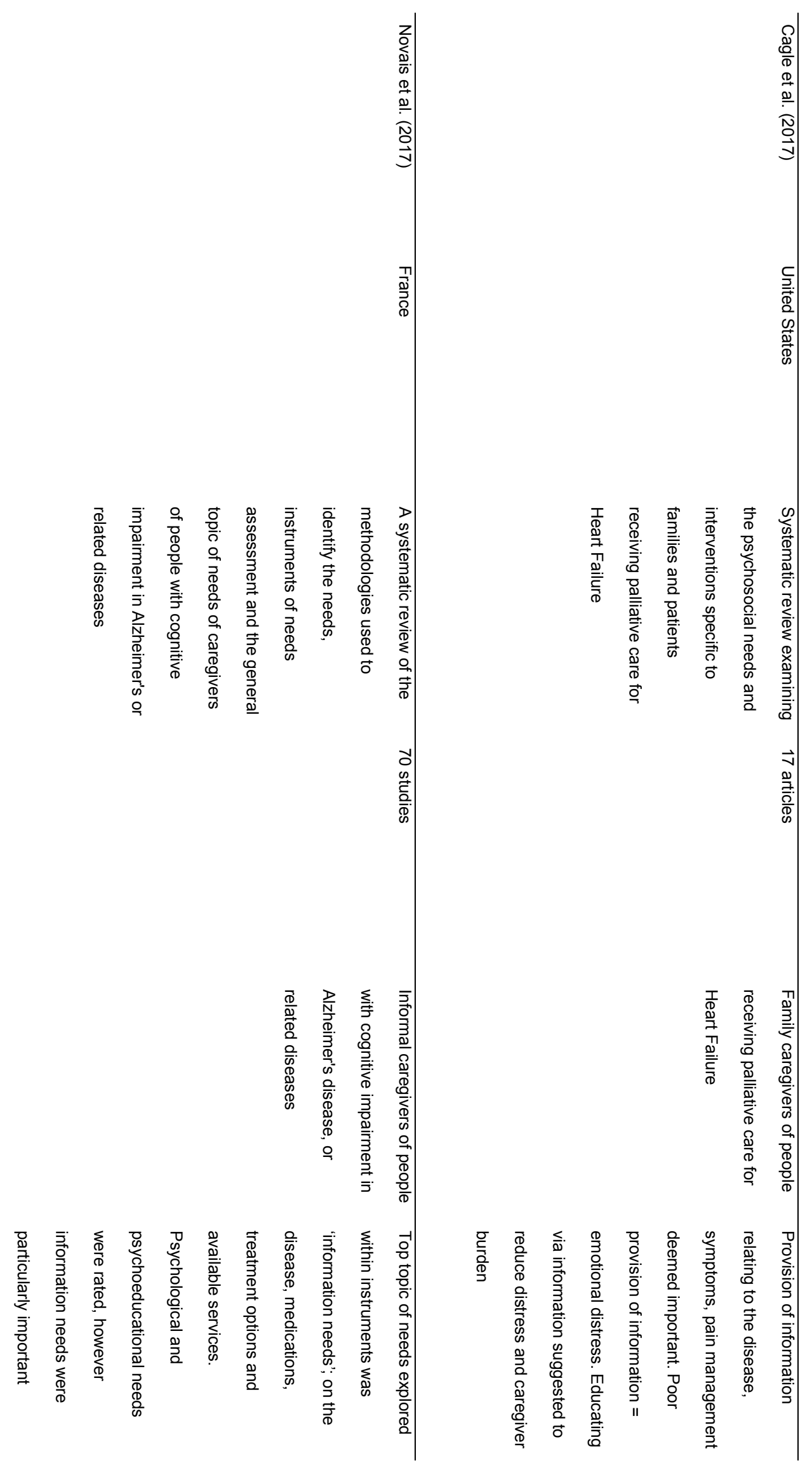




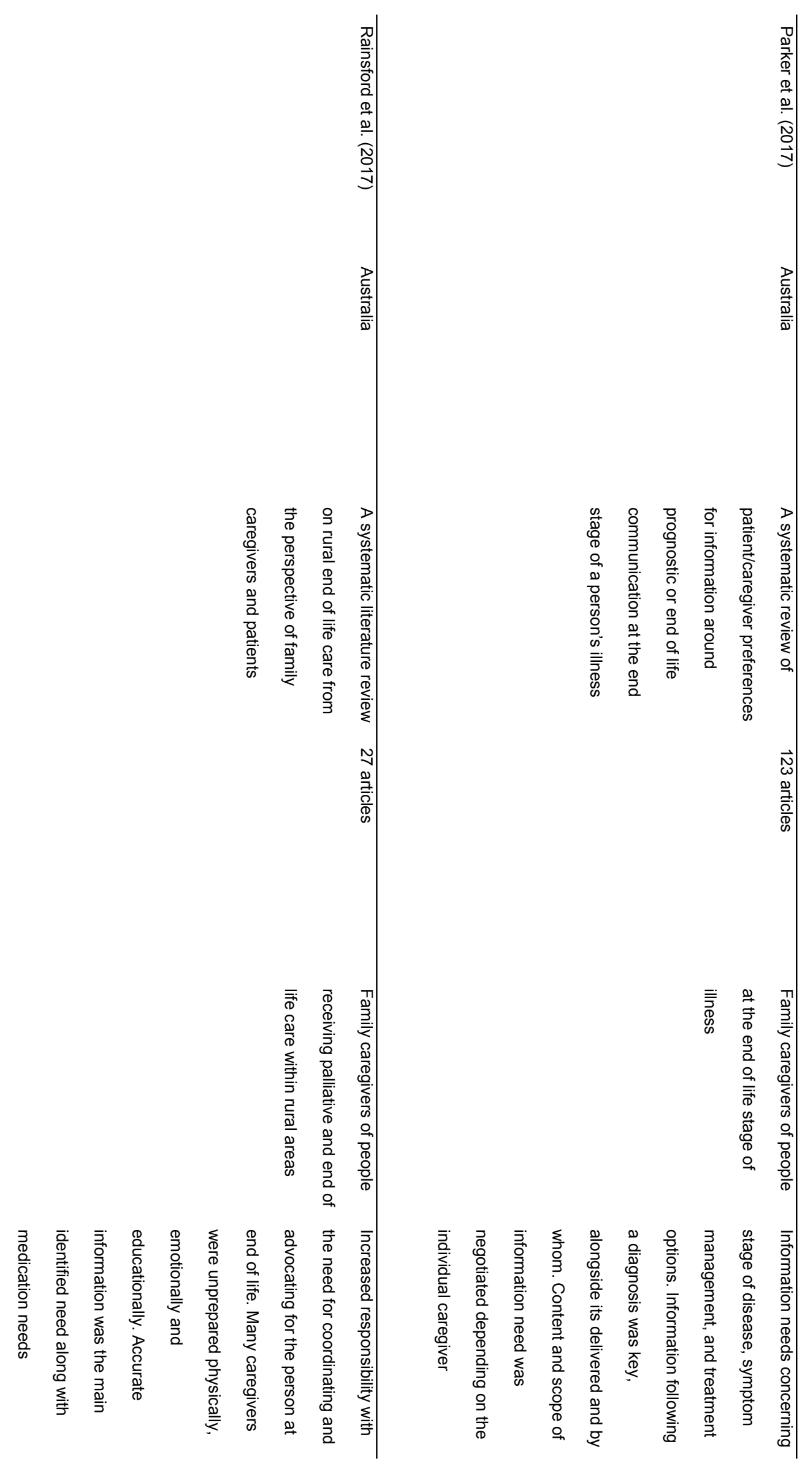




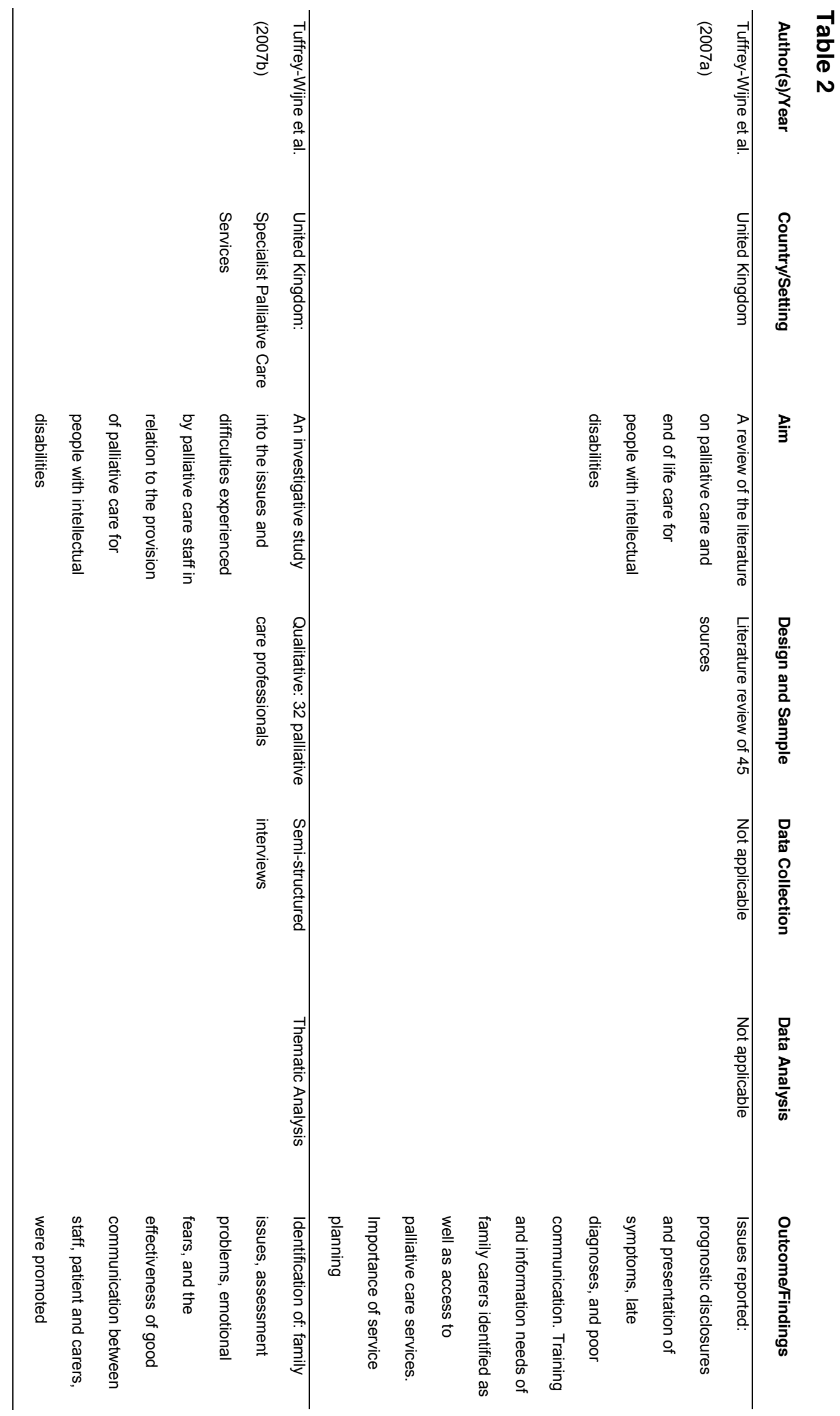




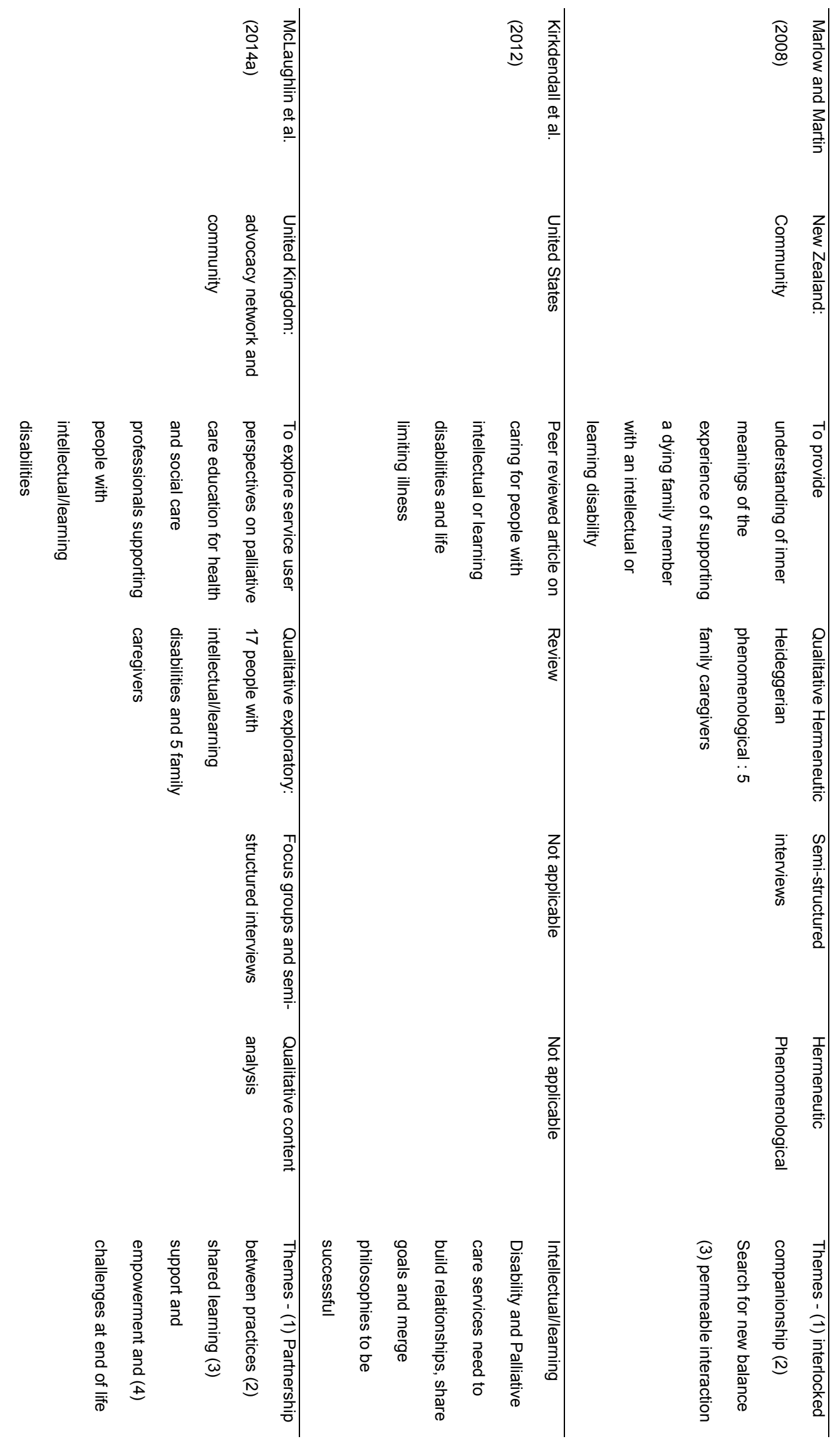




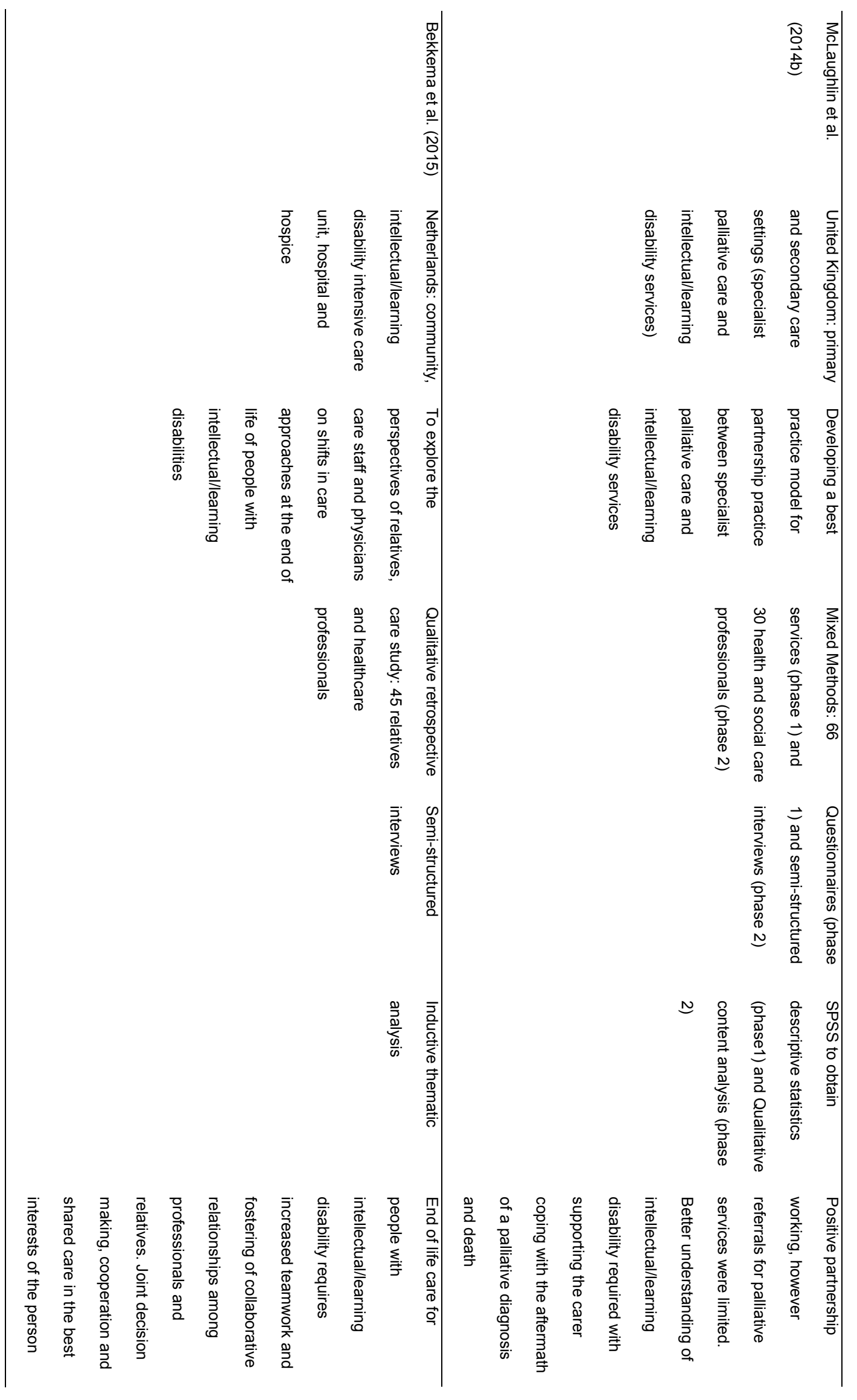




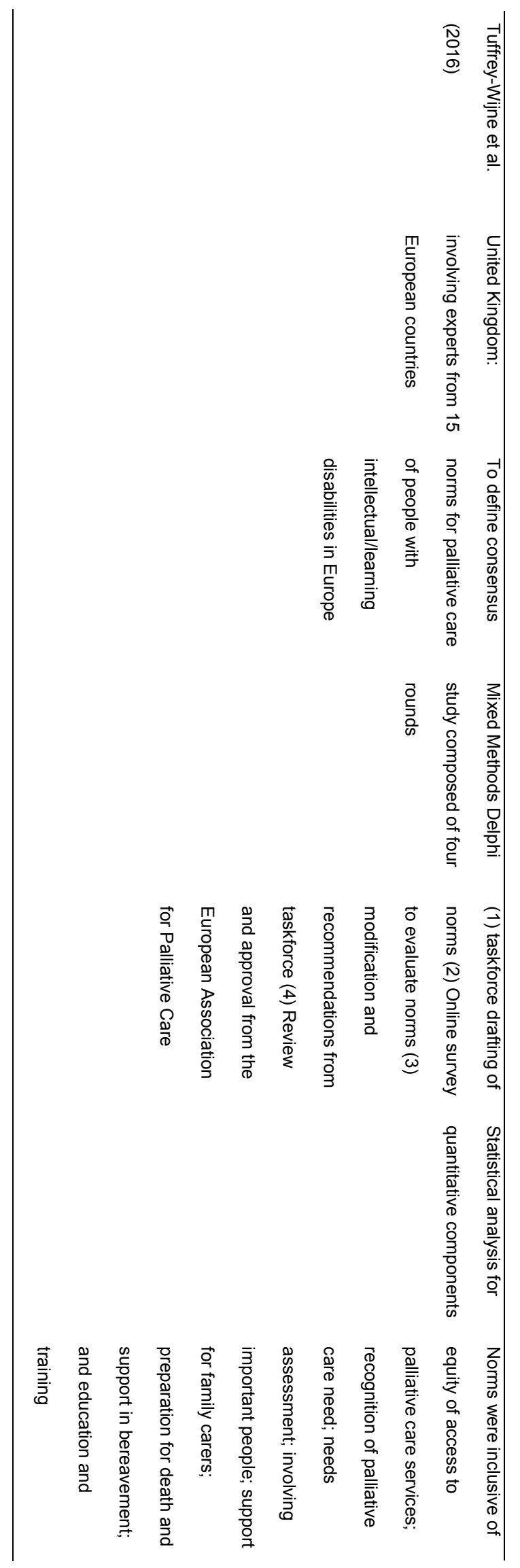

